\title{
Use of cost-effectiveness data in priority setting decisions: experiences from the national guidelines for heart diseases in Sweden
}

\author{
Nathalie Eckard ${ }^{1, *}$, Magnus Janzon $^{2}$, Lars-Åke Levin ${ }^{1}$
}

\section{Abstract}

Background: The inclusion of cost-effectiveness data, as a basis for priority setting rankings, is a distinguishing feature in the formulation of the Swedish national guidelines. Guidelines are generated with the direct intent to influence health policy and support decisions about the efficient allocation of scarce healthcare resources. Certain medical conditions may be given higher priority rankings i.e. given more resources than others, depending on how serious the medical condition is. This study investigated how a decision-making group, the Priority Setting Group (PSG), used cost-effectiveness data in ranking priority setting decisions in the national guidelines for heart diseases.

Methods: A qualitative case study methodology was used to explore the use of such data in ranking priority setting healthcare decisions. The study addressed availability of cost-effectiveness data, evidence understanding, interpretation difficulties, and the reliance on evidence. We were also interested in the explicit use of data in ranking decisions, especially in situations where economic arguments impacted the reasoning behind the decisions.

Results: This study showed that cost-effectiveness data was an important and integrated part of the decision-making process. Involvement of a health economist and reliance on the data facilitated the use of cost-effectiveness data. Economic arguments were used both as a fine-tuning instrument and a counterweight for dichotomization. Costeffectiveness data were used when the overall evidence base was weak and the decision-makers had trouble making decisions due to lack of clinical evidence and in times of uncertainty. Cost-effectiveness data were also used for decisions on the introduction of new expensive medical technologies.

Conclusion: Cost-effectiveness data matters in decision-making processes and the results of this study could be applicable to other jurisdictions where health economics is implemented in decision-making. This study contributes to knowledge on how cost-effectiveness data is used in actual decision-making, to ensure that the decisions are offered on equal terms and that patients receive medical care according their needs in order achieve maximum benefit. Keywords: Health Policy, Cost-Effectiveness, Policy Decision-Making, Priority Setting, Heart Diseases

Copyright: @ 2014 by Kerman University of Medical Sciences

Citation: Eckard N, Janzon M, Levin LÅ. Use of cost-effectiveness data in priority setting decisions: experiences from the national guidelines for heart diseases in Sweden. Int J Health Policy Manag 2014; 3: 323-332. doi: $10.15171 /$ ijhpm.2014.105

Article History:

Received: 2 July 2014

Accepted: 22 October 2014

ePublished: 27 October 2014

${ }^{*}$ Correspondence to:

Nathalie Eckard

Email: nathalie.eckard@liu.se

\section{Key Messages}

Implications for policy makers

- The inclusion of health economic aspects in the formulation of the Swedish national guidelines as a basis for priority setting rankings distinguishes them from the European counterparts.

- Despite the increased use of cost-effectiveness data in decision-making, little is known about the actual use of such data in actual decisionmaking.

- This study investigated how a decision-making group used cost-effectiveness data in ranking priority setting decisions in case of Swedish national guidelines for heart diseases, but the results could be applicable to other jurisdictions where health economics is implemented in decision-making.

- Cost-effectiveness data were used when the overall evidence base was weak and the decision-makers had trouble making decisions due to lack of clinical evidence and in times of uncertainty.

- Cost-effectiveness data matters in decision-making processes and policy-makers could benefit from the results of this study.

Implications for public

The ultimate goal of national guidelines is to contribute towards patients receiving high quality medical care. Clinical guidelines are generated with the direct intent to influence health policy and support decisions about the efficient allocation of scarce healthcare resources. Thus, decisionmakers, policy-makers and politicians must give recommendations on how resources should be allocated. Certain medical conditions may be given higher priority rankings i.e. given more resources than others, depending on how serious the medical condition is. An important aspect of guidelines is that they should be based on current scientific research. Clinical scientific data, economic and ethical considerations influence the decision made. This study contributes to knowledge on how cost-effectiveness data is used in actual decision-making, to ensure that the decisions are offered on equal terms and that patients receive medical care according their needs in order achieve maximum benefit. 


\section{Introduction}

The Swedish national guidelines use cost-effectiveness data as a basis for ranking decisions and Grip et al. reported that "health economics is an integrated part of the evidence base in the Swedish guidelines" (1). Cost-effectiveness data aid in the efficient management of scarce healthcare resources. Despite the increased production of cost-effectiveness data for decision-making, little is known about the actual use of such data. Empirical research has shown that Cost-Effectiveness Analysis (CEA), by themselves, have had limited impact on decision-makers $(2,3)$. The low impact level of economic analyses on such decisions has raised concerns $(4,5)$. Accessibility and acceptability barriers are often mentioned in the discussions of the limited impact or use of economic evaluation in decision-making (3). Having access to available evidence is important, though not sufficient, if the decisionmaker does not perceive cost-effectiveness evidence as acceptable. Scientific acceptability and institutional barriers have also been mentioned as a barrier in local decisionmaking (2). In Sweden, empirical research has shown that healthcare decision-makers at the local level have not yet accepted the use of cost-effectiveness evidence in their decision-making to the same extent as at the national level concerning pharmaceuticals (6).

This study aimed to investigate how a decision-making group used cost-effectiveness data in ranking priority setting decisions in case of Swedish national guidelines for heart diseases. The study addressed the availability of cost-effectiveness data, its understanding, interpretation difficulties, and the reliance on such evidence. We also investigated the explicit use of cost-effectiveness data in ranking decisions, especially situations where economic arguments impacted the reasoning behind the decisions.

\section{Setting}

The Swedish approach to priority setting is based on the ethics platform for making priority setting decisions in healthcare. These principles, in hierarchical order, are:

I. Human dignity principle: All individuals have equal value and rights regardless of their personal characteristics and social position.

II. Needs-solidarity principle: Healthcare resources should be allocated according to need.

III. Cost-effectiveness principle: Resources should be used in the most effective way without neglecting fundamental duties to improve health and quality of life (aimed at a reasonable relation between cost and effect) (7).

\section{National model for priority setting}

Since the above ethical principles give little guidance on their application in explicit decision-making, a national model for transparent priority setting has been developed to operationalize the contents of the above principles (8). Since 2000, the Swedish National Board of Health and Welfare (NBHW) has used this model in producing treatment guidelines. The NBHW has facilitated knowledge management and has provided methodological support for the development of evidence-based treatment guidelines.
Thus, according to Swedish law (9), care should be effective, evidence-based, patient focused, secure, and offered on equal terms.

The model includes several steps (Table 1) after the area for priority setting has been defined. The work process begins with "identifying the Prioritization Objects" (POs). The POs always consist of a medical condition-intervention pair. Both conditions and interventions must be present in a PO for the ethics platform to be fully implemented. Priority setting always means ranking something. The same intervention can be given different priorities depending on the medical conditions at which it is targeted. Step 1 represents the first box in Table 1. In order to create sufficient survey, the combinations of POs must be described in a uniform manner. According to the model, the POs should be clinically relevant rather than according to e.g. the specific design of a study. The aim of the PO is to give guidance in a specific decision situation in clinical practice. Thus, they could possibly be limited; focusing on typical cases in the daily routine, representing large volumes, and representing controversial areas where there are differences in praxis. They should also be based on decisions where the need for guidance for decision-makers is the greatest, e.g. expensive new treatments and in cases of uncertainty. Step 2 involves "reviewing and compiling current scientific knowledge and information". Qualified experts are tied to the areas concerned. Subsequently, several medical expert groups as well as a health economic expert group were involved in reviewing and compiling current available scientific knowledge to produce decision support. The experts conduct systematic literature searches. The experts compile information on the severity of a condition, the patient benefitrisk, and the cost-effectiveness. Step 3, which is the focus of this study, involves "producing a priority ranking decision". This is achieved by weighing the evidence. Each PO is ranked, based on the reviewed and compiled scientific knowledge provided by the expert groups. A consensus process is used to rank each PO (10) (Figure 1).

\section{Decision-making situation}

The Priority Setting Group (PSG) consisted of 21 persons, which included medical professionals (e.g. cardiologist, thoracic surgeon, and clinical physiologist), clinical professionals (e.g. nurse, physiotherapist, and primary care

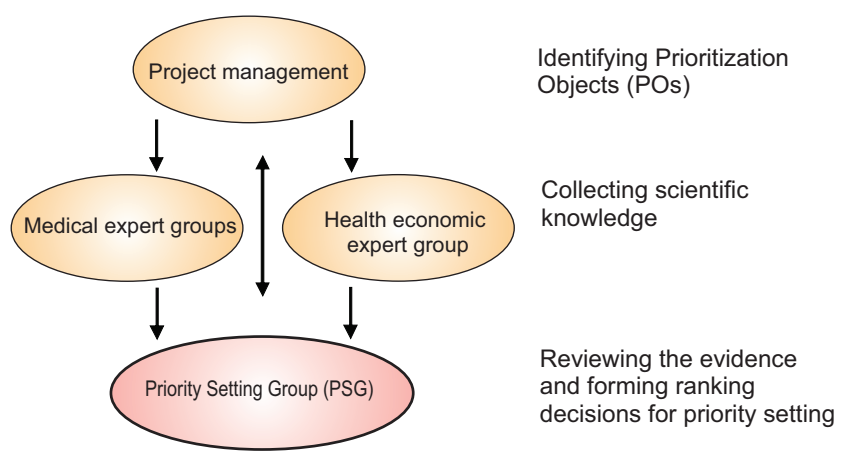

Figure 1. Priority setting decision-making at the national level. 
Table 1. Schematic description of the work process for the national guidelines

\begin{tabular}{|c|c|c|c|c|c|c|}
\hline $\begin{array}{l}\text { Medical condition } \\
\text { Intervention }\end{array}$ & $\begin{array}{l}\text { Severity of the } \\
\text { condition }\end{array}$ & $\begin{array}{c}\text { Effect of } \\
\text { intervention }\end{array}$ & Evidence of effect & $\begin{array}{c}\text { Cost per LY/ QALY } \\
\text { gained }\end{array}$ & $\begin{array}{c}\text { Health economic } \\
\text { evidence }\end{array}$ & Ranking \\
\hline 1 & & $2 \mathrm{~A}$ & & & & 3 \\
\hline
\end{tabular}

1: Medical conditions and interventions are identified and paired, forming Prioritization Objects (POs). The pairs should be clinically relevant, possibly limited, focused on typical cases, and should represent large volumes and controversial areas with differences in medical praxis.

The formal procedure consists of identifying current scientific knowledge through literature searches used as decision support.

2A: Medical expert groups review and compile current scientific knowledge of the severity of the condition, effect on intervention and evidence of effect.

2B: The health economic expert group reviews and compiles current scientific knowledge of cost-effectiveness, integrated in the medical review. 3: The Priority Setting Group (PSG) (decision-makers) produces a decision for each PO based on available evidence provided by the expert groups. The decisions are ranked on a scale from 1 to 10 for each medical condition and intervention.

Source: National guidelines for cardiac care 2008. Annex 3 to decision support documents - Method [modified] (10).

clinician), a health economist, and a medical ethicist. The PSG ranked decisions for priority setting, based on the available clinical evidence in relation to costs provided by medical and health economic expert groups. Thus, development of treatment guidelines involved operationalization of the model's contents into explicit ranking decisions. The model primarily aimed to guide policy decisions concerning patient groups at the national level. Before each meeting, the members of the PSG, in pairs, had specific responsibility for reading up on the scientific evidence related to certain POs i.e. they had "homework assignments". The work implied reviewing the evidence (the severity of the health condition, effect of treatment as well as its cost-effectiveness) provided by the expert groups. At each meeting, a preliminary proposal for ranking was presented (by the two PSG members with homework assignments), followed by a general discussion. A consensus process, i.e. justifying the proposal followed by open discussions, in order to reach a group ranking decision. Each PO was ranked on a scale ranging from 1 to 10 , with 1 denoting the highest priority intervention and 10 denoting the lowest. The PSG members have responsibility for all POs. A consensus process is used during the entire work process.

The PSG started its work process in late 2006. By late 2007, their works were being circulated and openly discussed at regional seminars across the country prior to the publication of the final version.

\section{Cost-effectiveness}

CEA always entails a choice between two or more comparable alternative treatment strategies. The results are often expressed in terms of cost per Quality-Adjusted Life-Year (QALY) gained. QALY combines quality of life with life years in relation to costs, and compares the value for money of alternative treatment strategies for a particular patient group. Lower costs for a more effective treatment strategy would imply that the intervention is considered to be dominant. However, decision-makers are often faced with interventions that are more effective but at an increased cost, i.e. they have to decide whether the society is willing to pay extra for a more effective treatment.

\section{Available evidence on cost-effectiveness}

The evidence presented to the PSG on cost-effectiveness studies on heart disease treatments was based on systematic literature searches conducted by the health economic expert group $(11,12)$. The overarching search term 'Heart Diseases' included several disease group areas and search terms within. The databases used to identify health economic analyses for the literature search were; NHS Economic Evaluation Database (NHS EED), Health Technology Assessment (HTA) Database, MEDLINE/PubMed and Cumulative Index to Nursing and Allied Health Literature (CINAHL).

The literature findings were presented in both short text descriptions and table formats for each PO, provided by the expert groups. The PSG either had access to this compiled information or cost-effectiveness data was lacking i.e. the work sheet was empty. Further, when cost-effectiveness data were lacking, simple model calculations were also conducted for certain POs where there was a need for guidance in clinical praxis were considered important and cost-effectiveness studies were lacking from the systematic literature searches e.g. catheter ablation treatment for atrial fibrillation. The worksheet included a box specifically for cost-effectiveness data and was, thus, an integral part of the evidence base (Table 1). As examples of use of cost-effectiveness data in the guidelines, we present the examples of implantable cardioverter defibrillators, catheter ablation treatment for atrial fibrillation and clopidogrel treatment in unstable angina.

\section{Methods}

This study adopted a qualitative case study methodology, that used observations and semi-structured interviews as primary source data, and accessed all documentations provided to the PSG.

\section{Data collection}

\section{Observations}

Observation is the systematic watching and detailed recording of what people say and do. It often highlights discrepancies between data generated from documentary analyses, interview research, and observed behavior. Observations were conducted with the purpose of studying how the PSG used cost-effectiveness data in its decisionmaking. Eleven full-day PSG meetings were held over the course of the work, of which three meetings were of two days. Field notes were taken during all the meetings. 
Interviews

An interview is a communicative event with a purpose. It is a structured conversation with an attempt "to understand the world from the subject's point of view" (13). A single investigator (NE) conducted all the face-to-face in-depth interviews of the PSG members. All the nine informants were approached after the PSG had completed its work, in order not to disturb the course of events during the work process. The sample represented geographic distribution, as well as all categories of specialty fields. The health economist was not included in the sample, as we were interested in how the decision-making group (non-economists), used available evidence that were not in their field of expertise. The interviews, were conducted using a semi-structured interview guide that addressed specific topics. All the interviews, which were between one to two hours, were recorded with assurances of confidentiality.

Semi-structured interview research questions, enabled one to pursue other issues or concerns raised by the informant. Moreover, in-depth interviews allowed the researcher to ask follow-up questions and provided the informants an opportunity to expand on the themes they find important. All interviews began with introductory questions in which the informants were asked to briefly describe their background and explain how they first came in contact with the PSG. Specific open-ended questions were then asked to capture their description of the tasks and the use of cost-effectiveness data in decision-making, as well as any social context issues.

\section{Data analysis}

All the notes from the observations and interviews were transcribed the same day or the day after the meeting, followed by data analysis. Initial coding was conducted to identify different statements, i.e. either descriptive or thematic, and to look for recurrent topics, and patterns in the observations and interviews (14). Validity concerns whether the researcher is reflecting the phenomena being studied, as perceived by the study population. Both internal and external validity are strongly linked. To verify the internal validation of data, the data has been compared to other sections of data (constant comparative method) and checked for different perspectives are not ignored or forced upon. To verify external validation of data, triangulation of sources has been partly used, comparing interview data with data from observations. The primary research questions formed a structure for categorizing the research data. New themes and sub-themes were identified throughout data collection and analysis, which are illustrated as quoted comments from the informants. Early frameworks and concepts were treated as being tentative and were repeatedly refined as new and existing data were analyzed.

\section{Results}

The findings include a systematic description and thematic analysis based on documents and observations of the meetings. The themes presented are accessibility (available cost-effectiveness data and level of understanding), acceptability (reliance and faith placed in the evidence) and use of cost-effectiveness data to form ranking decisions.
The PSG's task consisted of preparing ranking decisions, based on evidence-based knowledge, including cost-effectiveness, as part of the national model for priority setting.

The PSG members became acclimatized to the work method at an initial "boot camp" with verbal explanations of the task and through practical exercises. The key notions of the PSG working model were explained and instructions were also given to allocate resources between different treatments. After an anonymous vote, the group went through the different proposals and openly discussed the reasoning behind their ranking decision. The members were allowed to ask questions, justify their proposals, and listen to why other members of the group had a high or low ranking.

During the first meeting, the PSG received oral information from the project management on the basics of health economics, where cost-effectiveness was defined as "how much a society is willing to pay for a quality adjusted life year (QALY) and would imply that a medical intervention may be given a high priority even if the cost per QALY is considered high". The members were asked to remember that a high cost per QALY may be given a high priority ranking and a low cost per QALY may be given a low priority ranking. They were informed that interventions "are allowed to cost money", and that money used for one treatment strategy implies that another treatment strategy must give way. Reiteration strategy was used for reminding one another that all ranking decisions must be based on facts and evidence according to the national model.

\section{Accessibility}

The PSG either had access to compiled information or cost-effectiveness data was lacking i.e. the work sheet was empty. The worksheet included a box specifically for costeffectiveness data and was, thus, an integral part of the evidence base (Table 1). Cost-effectiveness data was available for 57 of the 331 POs. When cost-effectiveness data was available, the POs could be based on several underlying studies for each PO. For 139 of the POs, a qualified estimation (low-moderate-high cost per QALY) was made, by the health economic experts after consultation with the medical experts. Often, cost-effectiveness studies were lacking, i.e. the boxes were empty for 135 of the POs.

\section{Available cost-effectiveness data to inform decisions}

The informants reported that cost-effectiveness data are crucial for ranking priority setting decisions. A specific box for cost-effectiveness data in the worksheet also reinforced the belief that economic evidence is important for the decisionmaking process. One informant pointed out that the use of data in the decision-making process was something to be proud of - "we 'dared". Others pointed out that it distinguished the guidelines from their European counterparts, as the following comments highlights:

"It is a strength that other countries do not have. [...] In my experience, they are lagging [in Europe]".

The observations showed that PSG members were exposed to a lot of information before each meeting. The sheer number 
of POs in the guideline document was more than 300 . The members were consistently reminded, by the chairperson and the members of the steering committee, to include economic aspects while ranking the decisions.

\section{Level of understanding}

Several informants identified that they had limited access to in-depth written materials and also a limited understanding of health economics. One informant commented:

"I don't believe very many people have read this [the health economic facts document], and there is a widespread ignorance about it. So, there are short-comings in our understanding".

The informants were concerned about the lack of costeffectiveness data, and found it difficult to always make use of cost-effectiveness arguments in the decision-making process. A few informants questioned the results of model-based approaches and mentioned their limited understanding of the underlying assumptions in cost-effectiveness studies - for example:

"Now and then there were studies, but many boxes were empty. The health economic evidence base was a more or less weak foundation the whole time".

\section{Acceptability}

Reliance on the available evidence

The informants identified that there is an acceptance of and interest in health economics, specifically within the cardiovascular field, as the following comments suggest:

"There is a self confidence in heartcare. We know that we give 'value for money".

"Cardiologists have a higher awareness of health economics than do others in the medical profession".

The informants also perceived the health economist, who was present during the entire process, to be a credible representative of the health economic academic community.

"[Cost-effectiveness data] is built on a scientific foundation, and I have them utmost respect for the [health economic] field".

"I have the utmost respect for the fact that this is a knowledgeable person from the world of research making an educated guess".

A recurrent theme that the informants brought up was their reliance on a health economist during all meetings, as expressed by the following comment:

"When you are ignorant and don't understand something, you tend to disregard it and take some easy interpretations.

So I think the fact that they have put a health economist in place here means a lot".

A concern relating to poor levels of understanding was that too much faith might be placed on the use of cost-effectiveness data. An informant expressed that health economic evidence "becomes a 'truth" and another informant said that the costeffectiveness evidence was never questioned when available. Other informant comments connected to this theme are as follows:

"I believe that owing to general ignorance, when you don't understand something, you sometimes trust the written word and such, and there is this tendency, of course, because several big names [senior authorities] think this

[Health Economics] is an acceptable science".

An interesting finding was that other informants conveyed that their faith increased when the health economist identified and expressed the lack of evidence. Many informants realized that an evidence-based approach does not always signal the presence of Randomized Controlled Trials. It also involves accounting for the lack of evidence, indicating a limited evidence base, as the following quoted comments suggest:

"I appreciated the fact that [the health economist] also said there was no evidence. Evidence-based medicine is not about only finding the best studies with the highest grade of evidence, but also about expressing the lack of evidence. Indicating a lack of evidence and making an educated guess wins respect".

Another theme expressed by the informants was the use of cost-effectiveness data perceived as a means of obtaining healthcare resources such as new expensive medical technologies. One particular informant indicated that costeffectiveness data were not perceived as a threat but rather as a useful decision tool. An example of this theme is catheter ablation treatment which is illustrated later in this paper.

\section{Balancing available evidence}

The informants generalized that cost-effectiveness data were important in reaching a decision and that they do not primarily consider economic arguments. Most of them focused on the clinical effectiveness side because of their own area of expertise. They also expressed that they focused more on clinical effectiveness and the patient's needs. Costeffectiveness was not reviewed and challenged to the same extent as clinical evidence, as indicated in the following comments:

"Now and then, it came up, but not at all in the same manner as for those who had written the medical facts".

"You have to be a little pragmatic here. It [using costeffectiveness data] is so new still so new... if they'd taken a completely different approach and for each case and looked at the underlying studies, as they did here [evidence of effect], they would have wound up speaking to deaf ears... So it's, you know... it is a balancing act".

Thus, cost-effectiveness data were seen as a supplement to clinical evidence. Primarily, the informants considered both clinical effectiveness of the treatment and the associated risks when reaching a decision and secondly, cost-effectiveness data.

\section{Use of cost-effectiveness data to form ranking decisions Dichotomization}

Particular emphasis was placed on examining evidence that supports the PSG's ranking decisions and helps reach consensus decisions. When asked to reflect on situations when economic arguments were used in the decisions, a majority of informants had difficulty in isolating the costeffectiveness data from the collected evidence base. Many pointed out that they had doubts about using the evidence base when it was weak, although they had to take a position 
in order to reach consensus.

The findings suggest that the PSG found it difficult to spread the ranking decisions evenly on the 10 -grade scale. The group tends to award either a high or a low ranking, which resulted in a $U$-shaped curve, i.e. a majority of ranking decisions entailed either high or low rankings and were adapted to become a Yes or No answer. Of the 300 POs only 31 were ranked 5 or 6. Thus, dichotomizing the POs in terms of favoring (high rankings, 1 to 4 ) the medical condition and intervention or disfavoring (low rankings, 7 to 10) the treatments, was used as a solution in reaching consensus on the ranking decisions. The PSG found it difficult to reach a consensus in case of no evidence of clinical efficacy, and overall weak evidence base. The discussions were characterized by the need for new POs. Creating new POs was sometimes used as a strategy to advance the work forward, often resulting in dichotomization.

\section{Adjustment of ranking decisions}

Even if the informants had difficulty in giving examples of the specific use of cost-effectiveness data, the observations show that economic arguments were used after a preliminary ranking decision had been made that favored or disfavored the treatment. A ranking between 1 and 3 signaled that the PO will be carried out in medical praxis, a ranking of 4 to 6 signaled that it ought to be carried out, and a ranking of 7 to 10 signaled that it might be carried out. A ranking of 10 was indicated that a $\mathrm{PO}$ was used as an exception in medical praxis and only in cases of affordability. Thus, economic arguments were used in the group's deliberations after dichotomization to adjust the ranking decisions.

The availability of cost-effectiveness data did not always conclude that high cost-effectiveness ratios would imply lowranking decisions. Certain POs were given high rankings even though the cost per QALY was judged to be high. The PSG members interpreted that the society is willing to pay more for severe diseases - i.e. when need was considered, thereby, influencing the ranking decisions. The findings from the observations indicate that it was easier to reach consensus on ranking decisions for high rankings, even when costeffectiveness data on such strategies as life-saving intervention were lacking.

Examples of situations of the use of cost-effectiveness data The following examples have been chosen to highlight cases when the PSG made use of cost-effectiveness data in their decision-making.

\section{Implantable cardioverter defibrillators}

Cost-effectiveness data that were available for both secondary and primary preventive use of ICDs varied, depending on the risk for sudden death, from a moderate $(100,000 \leq$ 500,000 SEK) to a high $(500,000 \leq 1,000,000$ SEK) cost per QALY gained compared with the cost-effectiveness data for antiarrhythmic medical treatment. The higher the risk for sudden death, the lower the cost per QALY gained. The secondary preventive use of ICDs was given a ranking of 2 and the primary preventive use was given a ranking of 4 . Economic arguments were used during the group's deliberations focusing on the implication on budget impact of a high priority ranking decision. Arguments were based on the survival benefit for the patient population as a whole, including quality-of-life measures. The survival benefits were weighted against the increased cost of the device. Initially, the PSG made a decision in favor of the treatment and thereafter cost-effectiveness data was included in the discussion. The implications of the implementation of an expensive medical technology, such as ICD, was discussed. Although implantable ICDs are potentially life-saving devices for people at risk of sudden death as a result of cardiac arrhythmias, it was not given the highest ranking of 1 (Table 2).

\section{Catheter ablation treatment}

The PSG faced difficulty in reaching a ranking decision in the case of catheter ablation used for the treatment of patients suffering from symptomatic atrial fibrillation. Costeffectiveness data, in the form of a simple model calculation, had been provided by the health economic expert group for the group's deliberations. Thus, the steering committee identified a need for cost-effectiveness evidence, as a basis for the PSGs decision-making. The deliberations were adjourned several times in the course of the work, and significant time was spent considering the signal value of the decision. The group was concerned about the long-term efficacy of the treatment and a lack of cost-effectiveness data.

Despite its higher initial intervention costs, catheter ablation treatment was considered a cost-effective intervention compared with medical management and was estimated at a low ( $\leq 100,000$ SEK) cost per QALY gained for patients who previously failed to respond to medical management. The PO was finally given a ranking of 4 . The PSG's decision, reflects that new cost-effectiveness data have become available, justifying a ranking decision in favor of the treatment. Thus, the treatment ought to be considered as an alternative for patients who have not responded to previous medical management (Table 3).

\section{Clopidogrel plus Acetylsalicylic Acid (aspirin)}

Clopidogrel is used with Acetylsalicylic Acid (ASA) for the treatment of unstable angina as a secondary prevention of Percutaneous Coronary Intervention (PCI) for three to 12 months. Cost-effectiveness ratios were estimated at a low $(\leq 100,000$ SEK $)$ to moderate $(100,000 \leq 500,000$ SEK $)$ cost per QALY gained for the combination of clopidogrel and aspirin versus aspirin alone.

During the group's deliberations, the members' arguments primarily concerned the medical evidence, i.e. avoidance of ischemic events weighted against the excess risk of bleeding. The PO was finally given a high priority of 3 , reflecting the low cost-effectiveness ratios and the evidence which were available for the intervention (Table 4). (The high ranking decision may be viewed against the previous edition of the guidelines when clopidogrel was given a low ranking decision reflecting sparse cost-effectiveness evidence then available).

\section{Implications for healthcare organizations}

The PSG's ranking decisions have implications for the 
Table 2. Examples of priority setting ranking decisions for ICD

\begin{tabular}{|c|c|c|c|c|c|c|}
\hline $\begin{array}{l}\text { Medical condition } \\
\text { Intervention }\end{array}$ & $\begin{array}{l}\text { Severity of the } \\
\text { condition }\end{array}$ & Effect of intervention & $\begin{array}{l}\text { Evidence of } \\
\text { effect }\end{array}$ & $\begin{array}{l}\text { Cost per LY/ } \\
\text { QALY gained }\end{array}$ & $\begin{array}{l}\text { Health } \\
\text { economic } \\
\text { evidence }\end{array}$ & Ranking** \\
\hline $\begin{array}{l}\text { Risk of sudden death for patients } \\
\text { with ischemic heart disease, } \\
\text { impaired Ejection Fraction (EF } \\
\leq 35 \% \text { ) and function class NYHA II-III } \\
\text { at least } 3 \text { months after MI, in spite } \\
\text { of optimal medical management for } \\
\text { heart failure } \\
\text { ICD } \\
\text { (primary prophylaxis) }\end{array}$ & $\begin{array}{l}\text { High risk of } \\
\text { premature death. } \\
\text { Low to high need } \\
\text { of symptom relief. } \\
\text { Low to major } \\
\text { impact on quality } \\
\text { of life. }\end{array}$ & $\begin{array}{l}\text { Moderate to high } \\
\text { reduction of risk for } \\
\text { premature death. } \\
\text { No to low effect on } \\
\text { symptoms. Positive } \\
\text { to negative effect on } \\
\text { quality of life. Low } \\
\text { to moderate risk for } \\
\text { pre- and post-operative } \\
\text { complications. }\end{array}$ & $\begin{array}{l}\text { Evidence level } \\
1 \text { for reduction } \\
\text { of risk for } \\
\text { premature } \\
\text { death }\end{array}$ & $\begin{array}{l}\text { ICD vs. } \\
\text { conventional } \\
\text { medical } \\
\text { management } \\
\text { Moderate to } \\
\text { high* }\end{array}$ & $\begin{array}{l}\text { Good } \\
\text { scientific } \\
\text { evidence }\end{array}$ & 4 \\
\hline $\begin{array}{l}\text { Ventricular arrhythmia (VT/VF) } \\
\text { with cardiac arrest or syncope for } \\
\text { patients with/without impaired left } \\
\text { ventricular function } \\
\text { ICD } \\
\text { (secondary prophylaxis) }\end{array}$ & $\begin{array}{l}\text { High risk of } \\
\text { premature death. } \\
\text { High need of } \\
\text { symptom relief. } \\
\text { Major impact on } \\
\text { quality of life. }\end{array}$ & $\begin{array}{l}\text { Moderate to high } \\
\text { reduction of risk for } \\
\text { premature death. } \\
\text { Low to high reduction } \\
\text { on symptoms. No to } \\
\text { high improvement } \\
\text { on quality of life. Low } \\
\text { to moderate risk for } \\
\text { pre- and post-operative } \\
\text { complications. }\end{array}$ & $\begin{array}{l}\text { Evidence level } \\
1 \text { for reduction } \\
\text { of risk for } \\
\text { premature } \\
\text { death } \\
\text { compared } \\
\text { to medical } \\
\text { management }\end{array}$ & $\begin{array}{l}\text { ICD vs. } \\
\text { conventional } \\
\text { medical } \\
\text { management } \\
\text { Moderate to } \\
\text { high* }\end{array}$ & $\begin{array}{l}\text { Good } \\
\text { scientific } \\
\text { evidence }\end{array}$ & 2 \\
\hline
\end{tabular}

ICD= Implantable Cardioverter Defibrillator; LY= Life-Year; MI= Myocardial Infarction; NYHA= New York Heart Association; QALY= Quality-Adjusted Life-Year; VF= Ventricular Fibrillation; VT= Ventricular Tachycardia.

*Low [ $\leq 100,000$ SEK (11,000 Euro)]; Moderate [100,000 $\leq 500,000$ SEK $(11,000 \leq 55,000$ Euro)]; High $[500,000 \leq 1,000,000$ SEK (55,000 $\leq$ 111,000 Euro)]; Very high [>1,000,000 SEK (111,000 Euro)] cost per QALY gained.

**1 denotes an intervention with the highest priority ranking and 10 with the lowest.

Source: National guidelines for cardiac care 2008. Table annex to decision support document - Medical conditions and interventions for heart diseases [translated] (15).

Table 3. Example of a priority setting ranking decision for catheter ablation

\begin{tabular}{|c|c|c|c|c|c|c|}
\hline $\begin{array}{l}\text { Medical condition } \\
\text { Intervention }\end{array}$ & $\begin{array}{l}\text { Severity of the } \\
\text { condition }\end{array}$ & Effect of intervention & $\begin{array}{l}\text { Evidence of } \\
\text { effect }\end{array}$ & $\begin{array}{l}\text { Cost per LY/ } \\
\text { QALY gained }\end{array}$ & $\begin{array}{l}\text { Health } \\
\text { economic } \\
\text { evidence }\end{array}$ & Ranking** \\
\hline $\begin{array}{l}\text { Symptomatic or persistent } \\
\text { atrial fibrillation in spite of } \\
\text { adequate antiarrhythmic } \\
\text { medical management }\end{array}$ & $\begin{array}{l}\text { Low to moderate } \\
\text { risk of premature } \\
\text { death. } \\
\text { High need for } \\
\text { symptom relief. }\end{array}$ & $\begin{array}{l}\text { Favorable effect on symptomatic } \\
\text { atrial fibrillation ( } 56 \%-86 \%) \text {. } \\
1 \%-6 \% \text { serious complication } \\
\text { risk, including low mortality } \\
\text { risk. Unknown effect on risk of }\end{array}$ & $\begin{array}{l}\text { Good scientific } \\
\text { evidence }\end{array}$ & $\begin{array}{l}\text { Catheter } \\
\text { ablation vs. } \\
\text { antiarrhythmic } \\
\text { drug treatment }\end{array}$ & $\begin{array}{l}\text { Good } \\
\text { scientific } \\
\text { evidence }\end{array}$ & 4 \\
\hline
\end{tabular}

LY= Life-Year; QALY, Quality-Adjusted Life-Year.

*Low $[\leq 100,000$ SEK (11,000 Euro)]; Moderate $[100,000 \leq 500,000$ SEK $(11,000 \leq 55,000$ Euro)]; High $[500,000 \leq 1,000,000$ SEK (55,000 $\leq$ 111,000 Euro)]; Very high [ $>1,000,000$ SEK (111,000 Euro)] cost per QALY gained.

**1 denotes an intervention with the highest priority ranking and 10 with the lowest.

Source: National guidelines for cardiac care 2008. Table annex to decision support document - Medical conditions and interventions for heart diseases [translated] (15).

guidance of clinical decisions on a group level, as well as for resource allocation within cardiac care. We have already shown that economic arguments, such as implications for budget impact, were used during the group's deliberations in the case of ICDs. Another example of using economic arguments, was the case of warfarin (anticoagulation treatment) used for heart disease patients in the prevention of stroke. In the group discussion, the PSG recognized that preventive treatment in heart disease patients could have implications for the healthcare system as a whole and also reduce the costs to society by avoiding the costs related to stroke care. The informants mentioned that a societal perspective was included in the reasoning behind the ranking decisions, as highlighted by one informant:

"Considering - the healthcare system as a whole, rather than, a particular clinic".

The concept of the National Model for Transparent Prioritization in Swedish Health Care was not familiar to all the PSG members prior to their work. Producing priority ranking decisions by weighing evidence and including cost- 
Table 4. Example of priority setting ranking decision for Clopidogrel

\begin{tabular}{|c|c|c|c|c|c|c|}
\hline $\begin{array}{l}\text { Medical condition } \\
\text { Intervention }\end{array}$ & $\begin{array}{l}\text { Severity of } \\
\text { the condition }\end{array}$ & Effect of intervention & $\begin{array}{l}\text { Evidence of } \\
\text { effect }\end{array}$ & $\begin{array}{l}\text { Cost per LY/ } \\
\text { QALY gained }\end{array}$ & $\begin{array}{l}\text { Health } \\
\text { economic } \\
\text { evidence }\end{array}$ & Ranking** \\
\hline $\begin{array}{l}\text { Unstable coronary } \\
\text { artery disease }\end{array}$ & $\begin{array}{l}\text { Moderate risk } \\
\text { of premature } \\
\text { death }\end{array}$ & $\begin{array}{l}\text { ASA + clopidogrel, compared to ASA, reduced (non- } \\
\text { fatal } \mathrm{MI} \text {, stroke or cardiovascular death), from } 11.4 \\
\text { to } 9.3 \text { (RR=0.80, } \mathrm{Cl}=0.72-0.90 \text { ). } \\
\text { No significant difference in cardiovascular death }\end{array}$ & $\begin{array}{l}\text { Good } \\
\text { scientific } \\
\text { evidence }\end{array}$ & $\begin{array}{l}\text { Clopidogrel } \\
\text { vs. standard } \\
\text { treatment } \\
\text { (ASA) }\end{array}$ & $\begin{array}{l}\text { Good } \\
\text { scientific } \\
\text { evidence }\end{array}$ & 3 \\
\hline Clopidogrel plus & & separately. Increase in major bleeds from 2.7 to 3.7 & & & & \\
\hline
\end{tabular}

ASA= Acetylsalicylic Acid; Cl= Confidence Interval; LY= Life-Year; QALY= Quality-Adjusted life-Year; RR= Relative Risk.

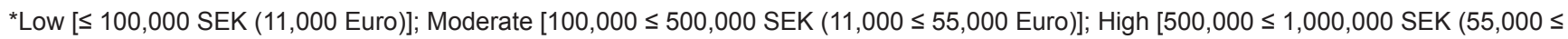

111,000 Euro)]; Very high [>1,000,000 SEK (111,000 Euro)] cost per QALY gained.

**1 denotes an intervention with the highest priority ranking and 10 with the lowest.

Source: National guidelines for cardiac care 2008. Table annex to decision support document - Medical conditions and interventions for heart diseases [translated] (15).

effectiveness data was perceived as a new way of thinking. One informant concluded in their interview that "affordability" is often a pressing issue at the local level of decision-making and in that sense associated as "something negative" and continued "but that is not what I associate with the term 'health economics' now". Instead, ethical considerations were emphasized as well as general discussions on what was considered "reasonable" investments.

\section{Discussion}

This study reports the findings of a case study on the national guidelines for heart diseases in Sweden (16). It uses qualitative methodology to explore various themes on the use of costeffectiveness data in priority setting ranking decisions. It addresses themes related to the availability of costeffectiveness data, understanding of the data, interpretation difficulties, and the reliance on the evidence.

Cost-effectiveness data were accessed in condensed text form and verbally through the health economist present at the PSG's meetings. The involvement of a health economist as a member of PSG and the steering committee reinforced the notion that health economics is important throughout the group's work.

This study supports the fact that healthcare decision-makers at the national level have accepted the use of cost-effectiveness in their decision-making process. We have given examples of situations where economic arguments were used in explicit decision-making. The group reasoned using economic considerations when the overall evidence base was weak and they had trouble taking decisions.

One problem mentioned was the lack of evidence, which implicated the faith placed in the evidence. Previous research has shown that even if economic arguments are significant, the expected benefits and risks of a treatment are the most important factors in making priority setting decisions (17). Others have reported several important reasons for drug priority setting and no single dominated in reaching a decision-making (18). Our findings also verify the notion that cost-effectiveness data are not challenged to the same extent as clinical evidence and that greater weight is given to the clinical effectiveness side.
A similar methodology was used in a UK study where costeffectiveness was used to structure the discussions and manage the complexity in the decision problem (19). The UK study included health economic experts as informants, thus, indicating that economic arguments were an important facilitating factor in the process. Moreover, the informants in the UK study had a more critical view and in-depth level of knowledge compared to our study. In our study, more than 300 POs were assessed compared to seven included in the UK study. Thus, less time was spent per appraisal topic. However, the findings of both the studies were largely similar.

The categories, accessibility and acceptability barriers are often mentioned in the discussions of the limited impact or use of economic evaluation in decision-making (3). Several studies have highlighted the difficulties decision-makers face in obtaining economic evaluations due to shortage of relevant analyses or problems accessing those published (2). Decision-makers often struggle with understanding health economic analyses given the concepts, language and presentation style. Acceptability barriers refer to all barriers that arise after economic evaluations have been accessed and understood, such as; scientific acceptability and institutional barriers (especially mentioned as a barrier in local decision-making) $(2,6)$.

Affordability is often a pressing issue at local level decisionmaking. Outcomes are seldom viewed in relation to cost, i.e. clinicians are often concerned with clinical effectiveness. Managers are often focused on reducing costs i.e. length of stay in hospital or expensive equipment. Neither view relates to both costs and effect. Thus, local level decision-makers often have no incentive to promote the status of economic evaluations as there is no framework to incorporate costeffectiveness data. Empirical research has shown that healthcare decision-makers at the local level have not yet accepted cost-effectiveness data to the same extent as at the national level.

This study, sheds light on a framework to incorporate costeffectiveness data in national level policy decision-making. Though, the decisions made by the PSG, are based on the severity of the disease and clinical effectiveness as well as costeffectiveness data. Economic evidence should be viewed as 
part of the evidence-based knowledge "package". It is not our intent to argue that healthcare priority setting should be based solely on cost-effectiveness data. The use of cost-effectiveness data represented one of many factors that play a part in health policy decision-making. A consideration is that most informants had difficulty isolating cost-effectiveness evidence, which represented a sub-component of the accumulated evidence base taken into account in decision-making.

There are several models to explain research utilization. In a knowledge-driven model, presenting and communicating policy-makers with research, is sufficient to ensure research use. Other models focus on research being compatible with the goals and needs of the decision-makers. An interactive model, on the other hand, implies a non-linear process of interconnections in order to make sense of the problem and research is seen as one part in a complicated process to reach decisions. Decision-making may also be viewed as a constellation of interests and pressures or tactical models to avoid responsibility for unpopular policy outcomes (20).

In Sweden, the ethics platform establishes the principles for priority setting in healthcare. The values underlying the ethics platform are that priorities are based on generally accepted principles, e.g. that the rankings must be perceived to be fair by most of the population to maintain confidence and the will to publically finance healthcare - a condition, that the government believes will facilitate understanding of the need to set priorities in healthcare. From an institutional design perspective, the delegation of institutional powers may be viewed as one among several tactics for politicians seeking to remove the challenge of setting limits to public services from the political agenda $(21,22)$. The delegators often enjoy a considerable degree of discretion. The work national guidelines for heart diseases is funded by the NBHW, who are commissioned by the Government and the Ministry of Social Affairs to coordinate the work. The decisions made by the PSG are not immediately binding and the decisions constitute recommendations. The NBHW also draws up a number of indicators of good standard of care and have implications for health services which are central for decision-makers.

The barriers of use may also be associated with institutional considerations such as; stated aims and goals, relationship to implementation, institutional affiliation of actors and external scrutiny levels (23). This study showed that the goals were clearly stated and there was a framework to organize the costeffectiveness data. This would increase the PSG's incentive to use the data in their decision-making. The fact that the PSG were struggling to understand presented evidence may have decreased the incentives to use the data. The relationship to implementation was indirect, as the decisions were not immediately binding and on the national level, and would increase the incentives of use. The affiliations of the actors in the PSG may help to explain the predominant clinicaleffectiveness used by the PSG members. The awareness of external scrutiny would also increase the incentives to use. If the guidelines are to be implemented and be perceived as legitimate and fair, it is important for all the PSG members to stand by all the decisions made by the group.

Using both observations and in-depth interview as a research methodology, is a strength in our study design. The participation in all PSG group meetings gave insight to the entire work process. The interviews supplemented the findings from the observations, giving a richness to the themes generated. However, our paper has limitations. Not all members of the PSG were interviewed. The sample sought to achieve broad representation. A limitation in our study may have been that the informants were clinicians working in a specialist unit and in the cardiovascular field and had a high awareness and wide-spread acceptance of the use of including cost-effectiveness data in ranking decisions. As with all qualitative research methodology, a concern was whether our findings are context specific or not. We believe that further research is needed on the inclusion of cost-effectiveness data in policy guidelines for other disease areas.

\section{Conclusion}

Cost-effectiveness data were concluded to be an important and integrated part of the decision-making process on the Swedish national guidelines for heart diseases. Involvement of a health economist and reliance on the data facilitated the use of data in the decision-making process. Economic arguments were a fine-tuning instrument and a counterweight for dichotomization. Cost-effectiveness data were used when the overall evidence base was weak and the PSG had trouble making decisions. Cost-effectiveness data were also used for decisions on the introduction of new expensive medical technologies.

\section{Acknowledgements}

We thank the National Board of Health and Welfare for granting us access to meetings and associated documents. We also thank the National Centre for Priority Setting for financial support. We are grateful to all anonymous informants without whom this study would not have been done.

\section{Ethical issues}

The research does not fall under the Swedish Law that regulates the ethics committees. Our data was agreed on by all research subjects.

\section{Competing interests}

The authors declare that they have no competing interests.

\section{Authors' contributions}

Each author has contributed to the study and the writing of this paper. Each author approves the version being submitted and certifies that the contents has not been published nor is being considered for publication elsewhere.

\section{Authors' affiliations}

'Division of Health Care Analysis, Department of Medical and Health Sciences, Linköping University, Linköping, Sweden. '2Department of Cardiology and Department of Medicine and Health Sciences, Linköping University, Linköping, Sweden.

\section{References}

1. Grip L, Lindahl B, Levin LA, Karvinge C, Eklund K, Wallentin L. From European to national guidelines on heart disease. Scand Cardiovasc J 2011; 45: 3-13. doi: $10.3109 / 14017431.2010 .536566$

2. Eddama $\mathrm{O}$, Coast $\mathrm{J}$. Use of economic evaluation in local 
health care decision-making in England: a qualitative investigation. Health Policy 2009; 89: 261-70. doi: 10.1016/j. healthpol.2008.06.004

3. Williams I, Bryan S. Understanding the limited impact of economic evaluation in health care resource allocation: a conceptual framework. Health Policy 2007; 80: 135-43. doi: 10.1016/j.healthpol.2006.03.006

4. Drummond M, Cooke J, Walley T. Economic evaluation under managed competition: evidence from the U.K. Soc Sci Med 1997; 45: 583-95.

5. Drummond $\mathrm{M}$, Weatherly $\mathrm{H}$. Implementing the findings of health technology assessments. If the CAT got out of the bag, can the TAIL wag the dog? Int J Technol Assess Health Care 2000; 16: $1-12$.

6. Ernoft S. The use of health economic evaluations in pharmaceutical priority setting. The case of Sweden [Dissertation]. Lund Business Press, Lund Institute of Economic Research: Lund University; 2010.

7. Priority setting in health care (1996/97:60), Ministry of Health and Social Affairs (1997).

8. Carlsson P, Kärvinge C, Broqvist M, Eklund K, Hallin B, Jacobsson $\mathrm{C}$, et al. Nationell modell för öppna vertikala prioriteringar inom svensk hälso- och sjukvård (The National model for open vertical prioritization in Swedish health care). Linköping: National Centre for Priority Setting in Health Care; 2007.

9. Health and Medical Service Act (SFS 1982:763), S. §2, Ministry of Health and Social Affairs (1982).

10. Nationella riktlinjer för hjärtsjukvård 2008. (National guidelines for cardiac care 2008). Bilaga 3 till beslutsstödsdokumentet Metod. (Annex to decision support documents - Method), 2008.

11. Eckard N, Janzon M, Levin LA. Compilation of costeffectiveness evidence for different heart conditions and treatment strategies. Scand Cardiovasc J 2011; 45: 72-6. doi: 10.3109/14017431.2011.557438

12. Nationella riktlinjer för hjärtsjukvård 2008. (National guidelines for cardiac care 2008). Bilaga 2 till beslutsstödsdokumentet - Det hälsoekonomiska faktadokumentet. (Annex to decision support documents - The health economic facts document), 2008.
13. Kvale S, Brinkmann S. Interviews: Learning the craft of qualitative research interviewing. Los Angeles: Sage Publications; 2009.

14. Graneheim UH, Lundman B. Qualitative content analysis in nursing research: concepts, procedures and measures to achieve trustworthiness. Nurse Educ Today 2004; 24: 105-12. doi: 10.1016/j.nedt.2003.10.001

15. Nationella riktlinjer för hjärtsjukvård 2008. (National guidelines for cardiac care 2008). Tabellbilaga till beslutsstödsdokumentet - tillstånds och åtgärdslista för hjärtsjukdomar. (Table annex to decision support documents - Medical conditions and interventions for herat diseases), 2008.

16. Nationella riktlinjer för hjärtsjukvård 2008. (National guidelines for cardiac care 2008). Beslutsstöd för prioriteringar. (Decision support for priority-setting), 2008.

17. Singer PA, Martin DK, Giacomini M, Purdy L. Priority setting for new technologies in medicine: qualitative case study. BMJ 2000; 321: 1316-8.

18. Hasman A, McIntosh E, Hope T. What reasons do those with practical experience use in deciding on priorities for healthcare resources? A qualitative study. J Med Ethics 2008; 34: 658-63. doi: 10.1136/jme.2007.023366

19. Bryan S, Williams I, Mclver S. Seeing the NICE side of costeffectiveness analysis: a qualitative investigation of the use of CEA in NICE technology appraisals. Health Econ 2007; 16: 17993. doi: $10.1002 /$ hec. 1133

20. Weiss C. The Many Meanings of Research Utilization. Public Adm Rev 1979; 39: 426-31.

21. Landwehr C, Böhm K. Delegation and institutional design in health-care rationing. Governance 2011; 4: 665-88.

22. Landwehr $\mathrm{C}$, Nedlund AC. Legitimacy Problems in the Allocation of Health Care: Decision-making Procedures in International Comparison. In: Bluhdorn I, editor. Search of Legitimacy Policy Making in Europe and the Challenge of Complexity: Barbara Budrich Publishers; 2009.

23. Williams I. Institutuions, cost-effectiveness analysis and healthcare rationing: the example of healthcare coverage in the English National Health Service. Policy Polit 2013; 41: 223-39. 